\title{
Elizabeth Grinage
}

\section{Spiritual Significances of Vodoun as Demonstrated in Stout's Recurring Damballah Dream}

Elizabeth Grinage is a junior studying English and Women, Gender, and Sexuality Studies. Elizabeth is from Lawrence, Kansas. This research was supervised by Dr. Giselle Anatol of the English Department.

Abstract: In this art exhibition paper, I work to demonstrate a more accurate examination of Vodoun culture and values than is often portrayed in mainstream American media. I use Reneé Stout's lithographic print Recurring Damballah Dream as a lens through which to analyze emblems of Vodoun culture, specifically within practices in Haiti and Louisiana, demonstrating the complexity and significance of Vodoun as a healing culture. Using Disney's The Princess and The Frog as an example of an American misrepresentation of Vodoun, I attempt to characterize the ways in which Vodoun is belittled and demonized within colonial frameworks, projecting racial discrimination onto its practitioners.

Vodoun is a complex and significant Afro-Caribbean healing tradition that originated in Haiti but whose roots are traceable to African traditional religion. Though practiced largely across the African diaspora, where it is known by a variety of other names and terms, this essay will address Vodoun specifically as practiced in Haiti and Louisiana - the geographical cultures conveyed in Renée Stout's 1999 lithographic print Recurring Damballah Dream. I will use the term "Vodoun" throughout this essay, instead of other interchangeable names, both for the sake of consistency and because of its presence in multiple referenced sources throughout this essay. Through an analysis of various images in Stout's print and a discussion of other instances in which similar images are portrayed, I will demonstrate a more accurate examination of Vodoun culture and values than is often portrayed in mainstream American media. Specifically, I will use Disney's The Princess and the Frog as an example of how American popular culture often demonizes the spiritual complexities of Haitian religious expressions and to demonstrate that, by re-centering our understanding of the culture on its practitioners, we can deconstruct such misrepresentations to gain more accurate insight into Vodoun cultural practices. This essay examines Stout's Recurring Damballah Dream as one means of deconstructing such distortions of Vodoun; it ultimately aims to characterize Vodoun culture as a complex and unique tradition 
that provides the practitioner not only with a sort of supernatural power, but with opportunities for personal empowerment, protection, and spiritual guidance.

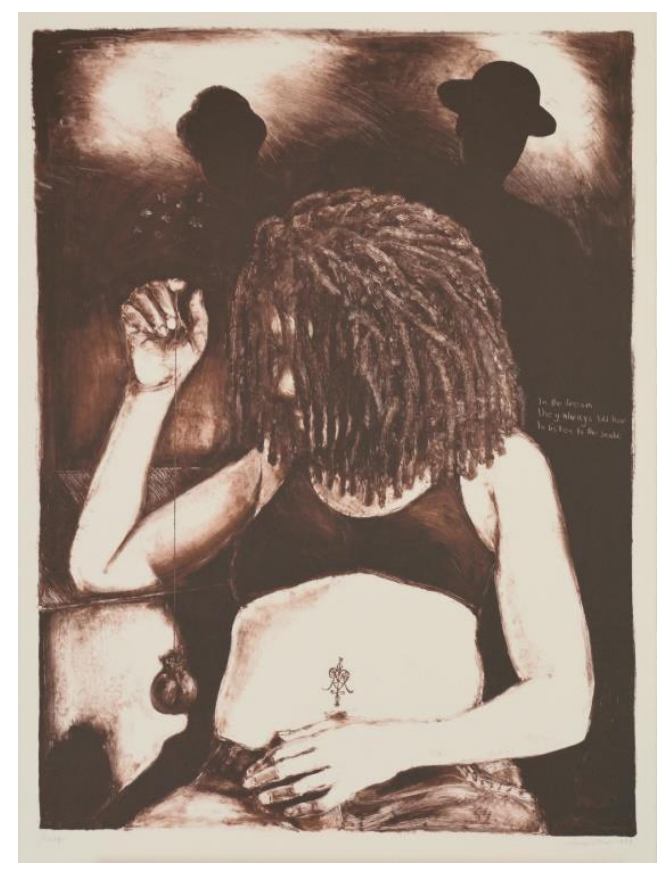

Stout, Renée. Recurring Damballah Dream. 1999. Flint Institute of Arts, www.flintarts.org/art/objects/9206.

Throughout this paper, I will refer to the subject of the print as Stout herself, because of the physical resemblance between them. In the print, the Gris Gris Bag at which Stout gazes, holding it from its string, demonstrates the potential for her to draw on the Vodoun power of healing. A Gris Gris Bag, also known as a "Mojo Bag," is an adornment prescribed by Vodoun practitioners that is generally worn under one's clothes to be in contact with skin. It is filled with various roots and curative substances which are specific to the protection of the wearer. Another of Stout's pieces entitled Root Chart \#1 illustrates six roots and their various powers within Vodoun culture; the roots are characterized by their abilities to provide protection, purification, and luck, but listed also are distinctions such as "female" and "male version[s]," their use "for the home," and their "[enhanced power] when combined with other roots." Similar distinctions between the significances of roots in Vodoun tradition are made in Maryse Conde's I, Tituba, Black Witch of Salem. When Tituba begins learning the practice of Vodoun from Mama Yaya, Mama Yaya takes care to note differences between herbal treatments: "Those for inducing sleep. Those for healing wounds and ulcers. Those for loosening the tongues of thieves..." (Condé 9). Such specifications, not just between different types of roots but according to their shapes and how they are combined with other roots for various purposes, demonstrate the complex and individualized nature of the Gris Gris Bag in Vodoun tradition. 
Though healing traditions within Vodoun culture vary between specific ritual engagements, Danielle Clausnitzer characterizes the protective power of the Gris Gris Bag as "contained within the believers' ability to imbue them with spiritual authority" (1). Stout is depicted holding and gazing at a Gris Gris Bag hanging from a string, presumably in a moment of indecision as to whether she will wear it and give it the power of spiritual authority that Clausnitzer demonstrates is within her ability. Such contemplation over the power of Vodoun is demonstrated also in Condé's novel: Tituba is presented with many moments of indecision where she must choose whether to use the power of Vodoun to protect herself. After calling on her abilities to harm Susanna Endicott, a vindictive woman to whom her husband is enslaved, Tituba only uses them to help others, specifically Betsey Parris. The novel's depiction of Vodoun as powerful, significant, and requiring contemplation before practicing can likewise be read in the Stout's contemplation over the utilization of the Gris Gris Bag.

Aside from the Gris Gris Bag as an emblem of Vodoun, the very title of Stout's Recurring Damballah Dream is symbolic of Vodoun culture; it suggests that Stout is communicating with a loa, or Haitian deity, who encourages her to utilize the power of Vodoun. As with Gris Gris Bags, interpretations of Vodoun spirits such as Damballah fluctuate between cultures, but according to the abstract preceding Aseret Sin's poem on the subject, "Damballah is a serpent loa who represents ravage and regeneration as well as power, creation, virility, and sensuality" (149). The male spirit Damballah is often depicted in accordance with the female spirit Aido-Hwedo- "as twin serpents entwined in conjugal bliss around the tree of life"-and the two shadowy figures in Stout's print are reminiscent of this pair (149). Stout is portrayed bathed in light at the foreground of the piece while the two figures stand behind her with some sort of light shining from behind them, suggesting that they may be of supernatural nature. The inscription to the right of Stout, which reads "[i]n the dream they always tell her to listen to the snake," indicates that the two figures are not physical embodiments of Damballah and Aido-Hwedo, but rather messengers that encourage her communication with spirits in the dream world.

In Haitian culture, such communication with the spirit world is a common characteristic of dreams; dreams "function as one of the vehicles of communication between the gods, the dead, and the living" (Bourguignon 264). Stout's recurring dream is a means of communication between herself and Damballah in which the messengers could be communicating with her "a generalized demand for the fulfilment of religious obligations" (268). When taking into consideration the role of dreams as culturally insightful, it seems likely that Damballah is encouraging Stout to wear the Gris Gris Bag and practice Vodoun traditions. The significance of dreams within Vodoun practice, however, is not exclusive to Haitian culture. In Condé's novel, Tituba - from Barbados - comments on a similar power of dreams and the night as "[a] great crossroads where the present takes the past by hand, where the living and the dead merge" (121). Though Tituba's dreams provide for her a means of communication with the dead rather than 
the loa, both Tituba and Stout credit their dreams with an ability to connect with and receive help from spiritual entities in a different manner than they could in the day when awake.

Aside from Damballah's encouragement that is demonstrated in the print, Stout is portrayed as possessing spiritual protection by the Erzulie Freda veve depicted on her belly. In Vodoun culture, the Erzulie Freda veve is associated with both the Virgin Mary and sensuality, and she is commonly depicted as a biracial woman. Her biracial identity presents a significant contrast to the suppression of female sexuality often found in Western society, where women of color in particular are viewed merely as sexual objects without independent sensual desires, yet white women are adulated as "the ultimate object of sexual desire" (Bragg 155). In Beauty Bragg's citation of Joan Dayan, such suppression of Black female sexuality can be exemplified by the sexual and racial domination of enslaved Black women whose "violation" ensured "the spiritualized, refined images of white women"'; existing even outside the bounds of slavery, Dayan asserts "the free woman of color would be served, fed, honored, and adored, and at the same time excluded from marriage, threatened by poverty, and often abandoned'" (155).

The print's depiction of Stout corresponds with such clashing expectations of repressed and expressed sexuality: her breasts are fully covered though much of her belly and arms are uncovered. In coherence with such a dichotomy, Joan Dayan's argument that Erzulie Freda "signifies the 'splitting of women into objects to be desired or feared'" highlights the multifaceted internal power of reclamation with which Vodoun has imbued Stout (154). The placement of the Erzulie Freda on Stout's uncovered belly suggests the role of both mother and sensual being that Erzulie Freda represents, and her power to grant "a generalized spirit of resistance" can be read as Stout's chance to reclaim comfort in her sexuality that has been demeaned and corrupted by colonial racial domination (156). As with the Gris Gris Bag, Vodoun practice presents Stout with an opportunity, this time to embrace the power of the Erzulie Freda which-like Damballahstands as a representation of reclaimed sensuality.

Just as we see a corruption of Black sexuality within colonial domination, there exists a corrupted image of Vodoun culture in mainstream American media (Anatol 1). Customs of Vodoun practice are skewed, depicted as nonsensical, satanic, or romanticized in a way that discredits them for being irrational (1). For instance, in Disney's The Princess and the Frog, Dr. Facilier is a villainous Vodoun practitioner who fits into the inaccurate, satanic depiction of the culture, using the power of Vodoun in an attempt to trick Prince Naveen and ultimately steal Charlotte La Bouff's fortune. In his performance of "I've Got Friends on the Other Side," he wields his "friends on the other side" as a threat, suggesting that they provide him with unlimited power. The performance likewise includes images of snakes reminiscent of the serpent loa, appearing first in Dr. Facilier's shadow and then tying Prince Naveen to his chair (The Princess and the Frog 19:12, 21:20). Here, the serpent loa Damballah — who signifies power and creation in 
Haitian Vodoun - is corrupted by the Christian image of snakes as symbols of evil, creating a direct association between Dr. Facilier and Satan. Moreover, it appears that Dr. Facilier can call on his dead spirit "friends" at any time he pleases, without having to dream or sacrifice animals as Tituba does in Conde's novel. Because Dr. Facilier is only motivated by material wealth, this depiction of Vodoun misrepresents the tradition as one rooted in capitalist values rather than the personal protection and empowerment seen in Stout's print.

In contrast to Dr. Facilier, Mama Odie's depiction of Vodoun portrays the culture as romanticized yet nonsensical. Mama Odie's version of Vodoun is consistent with Christian values that concern the moral development of Tiana and Prince Naveen: "when you find out who you are, you'll find out what you need" (1:03:43). Rather than offering the complex cultural security we see in Stout's print, Mama Odie's number implies that Vodoun will allow Tiana and Prince Naveen to simply reevaluate their situation to find worldly happiness. As with Dr. Facilier's song, the song "Dig a Little Deeper" includes depictions of a snake, Mama Odie first dancing with it, then wrapping it around her fingers like jewelry (1:03:11). Though Mama Odie's number does not blatantly discourage the practice of Vodoun, the representation is dangerously flippant; by falsely depicting it as a means of mindless entertainment with a whimsical dance into the sunshine, Mama Odie's number reinforces the simplistic and demeaning portrayal of Vodoun as a superficial, jovial practice, useful only as a performative escape. Both depictions of Vodoun culture represented by Dr. Facilier and Mama Odie pervert and demean the spiritual significance and complexity of the tradition. Such inaccurate stereotypes skew the understandings of Vodoun from a culture intended to heal and protect to the very harmful images of one that is rooted in evil, exoticized, or completely disregarded as childish and unimportant.

Vodoun practice holds meaningful cultural relevance throughout the African Diaspora as a healing and protective tradition. Stout specifically examines the significance of Vodoun culture as it is practiced in America and influenced by Haitian ritual, and in studying her Recurring Damballah Dream and its allusions to different Vodoun beliefs, we can gain a more accurate understanding of how Vodoun empowers and offers security to its practitioners. By contrast, in examining depictions of Vodoun in popular culture, we can see how symbols of the culture are misrepresented through a colonial lens, reinforcing harmful and inaccurate stereotypes of Vodoun as satanic or unrealistic and unimportant. Such stereotypes project onto Vodoun practitioners contempt and further racial discrimination, enforcing the assumption that any Black person could be partaking in this 'satanic' or 'inconsequential' religion. Inaccurate portrayals of Vodoun go far beyond cultivating misunderstandings of the culture; they demonstrate the unwillingness of Western society to accept other cultures as equally significant and complex as its own. Such clear attempts to ostracize and demonize Vodoun demean its cultural importance and its ability to provide its practitioners with the spiritual connection, protection, and comfort we see in Condé's novel and Stout's print. 


\section{References}

Anatol, Giselle. "Week 6: Conjure, Mojo, "Voodoo," and Hoodoo." Synopsis of Tanya Krzywinska's $A$ skin for dancing in: possession, witchcraft and voodoo in film, Black Speculative Fiction, Fall 2020, University of Kansas, Blackboard.com.

Bourguignon, Erika E. "Dreams and Dream Interpretation in Haiti." American Anthropological Association, vol. 56, no. 2, pp. 262-268.

Bragg, Beauty. "Chapter Nine: Edwidge Danticat's Breath, Eyes, Memory: Historicizing the Colonial Woman." Literary Expressions of African Spirituality, edited by Carol P. Marsh-Lockett and Elizabeth J. West, Lexington Books, 2013, pp. 163-182.

Clausnitzer, Danielle. "Adorned by Power: The Individualized Experience of the Mojo Bag." Religions, vol. 8 , no. 10, 2017, pp. 1-8.

Condé, Maryse. I, Tituba, Black Witch of Salem. Transl. by Richard Philcox, University of Virginia Press, 1992.

The Princess and the Frog. Directed by John Musker and Ron Clements, voice acting by Keith David and Jennifer Lewis, Disney Animated Studios, 2009.

Sin, Aseret. "POETRIX." Femspec, vol. 6, no. 1, 2005, p. 149.

Stout, Renée. Recurring Damballah Dream. 1999, Spencer Museum of Art, Lawrence, Kansas.

Stout, Renée. Root Chart \#1. 2006, Brosseau Learning Center, Lawrence, Kansas. 